\title{
Asymptomatic liver disease in hepatitis B antigen carriers
}

\author{
I. L. WOOLF, B. E. BOYES, D. M. JONES, J. S. WHITTAKER, E. TAPP, \\ R. N. M. MacSWEEN, P. H. RENTON, F. STRATTON, AND I. W. DYMOCK 1 \\ From the Departments of Medicine, Pathology, and Bacteriology, University Hospital of South Manchester, \\ The National Blood Transfusion Service, Manchester, and the University Department of Pathology, \\ Western Infirmary, Glasgow.
}

SYNOPSIS Thirty-four healthy blood donors, found to be persistent HBAg carriers, have been investigated by means of serial liver function tests, bromsulphthalein (BSP) retention, and liver biopsy. Thirty-one of the donors had histological abnormalities including one with cirrhosis, three with chronic aggressive hepatitis, and 11 with chronic persistent hepatitis. In 13 biopsies there were focal areas of necrosis in the liver parenchyma. Serial liver function tests revealed abnormalities in each of the donors with cirrhosis or with chronic aggressive hepatitis, in seven of the 11 donors with chronic persistent hepatitis, and in seven of the 13 with focal parenchymal necrosis. The degree of $\vec{\varphi}$ BSP retention was greatest $(>11 \%)$ in the donors with chronic aggressive hepatitis. The severity of the histological changes was related neither to the titre of the antigen in the serum nor to the presence of autoantibodies.

The association of the hepatitis B antigen (HBAg, Australia antigen, HAA) with serum hepatitis is now well established. It is also being increasingly implicated in chronic liver disease (Krohn, Finlayson, Jokelainen, Anderson, and Prince, 1970; Hadziyannis, Merikas, and Afroudakis, 1970; Dudley, Fox, and Sherlock, 1971).

The routine screening of donor blood by blood transfusion services has identified substantial numbers of asymptomatic HBAg carriers (Kliman, Reid, Lilly, and Morrison, 1971; Wallace, Milne, and Barr, 1972) although the full implications of this carrier state remain to be determined. Several reports from other countries have recorded a varying incidence of liver abnormalities (Singleton, Fitch, Merrill, Kohler, and Rettberg, 1971; Bolin, Davis, and Liddelow, 1973). This report records our findings in a group of healthy asymptomatic volunteer blood donors in the north west of England.

\section{Patients and Methods}

Screening of donor blood for the presence of HBAg was begun in March 1970 using immunoelectroosmophoresis (Stratton, 1972). All positive tests were confirmed by an independent laboratory ${ }^{2}$ Correspondence to: Dr. I. W. Dymock, Department of Medicine, University Hospital of South Manchester, Manchester M20 8LR, England.

Received for publication 4 March 1974.
(Public Health Laboratory Service, Manchester) using similar methodology. The results of positive tests were reported to the family practitioners, with whose consent arrangements were subsequently made for these donors to be reviewed in the Liver Clinic at the University Hospital of South Manchester.

Thirty-four donors who had persistent antigenaemia were investigated for evidence of liver disease. In each donor an attempt was made by careful questioning to elicit a possible source of infection. The investigations performed included a serum 웅 bilirubin, alkaline phosphatase, aspartate and $D$ alanine aminotransferases (SGOT/SGPT), albumin and globulin levels, protein electrophoresis, and pro- $N$ thrombin time. These tests were performed at three monthly intervals over a period of one to two years. $N$ Using standard indirect immunofluorescence tech- N nique the sera were screened for smooth muscle anti- $\overline{-}$ body (Johnson, Holborow, and Glynn, 1965), antinuclear factor (Beck, 1961), and antimitochondrial

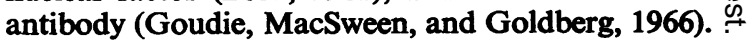
Each donor was admitted to hospital where a $\underline{T}$ bromsulphthalein (BSP) retention test and liver biopsy were performed.

\section{Results}

The mean age of the donors was 33.6 years (range 
19-58 years). Twenty-five were male and nine were female. A history of possible exposure to HBAg in the past was elicited in 19 of the 34 donors (table I). More than one possible source was identifiable in five. None of the donors admitted to the use of illicit drugs, although one admitted mixing in circles where such drugs were taken. The only clinical abnormality was minor hepatomegaly which was present in three donors.

\begin{tabular}{lc}
\hline Source & No. of Donors \\
\hline Contact with hepatitis & 10 \\
Previous blood transfusion & 5 \\
Tattooing & 4 \\
Malarial infection & 4 \\
Hospital employment & 2 \\
Contact with illicit drug users & 1 \\
\hline
\end{tabular}

Table I Possible sources of exposure to the hepatitis antigen

HEPATITIS B ANTIGEN CARRIAGE

All the donors studied remained carriers of HBAg throughout the study. Sera taken at the time of liver biopsy were tested in dilution by immunoelectroosmophoresis. Titres varied between antigen detectable only in undiluted serum to those in which it was detected at a dilution of $1 / 128$. There was no correlation between antigen titre and the extent of either the biochemical or the histological changes.

\section{SERUM AUTOANTIBODIES}

In three donors the test for antinuclear factor was positive at a titre of $1 / 16$ and in each the staining pattern was homogeneous. These three samples were from donors with chronic persistent hepatitis. Tests for smooth muscle antibody (SMA) were weakly positive at a titre of $\frac{1}{8}$ in one donor and one further serum gave a weakly positive test for mitochondrial antibody (MAB) also at a titre of $\frac{1}{8}$. In no instance was more than one test positive. None of the donors with aggressive hepatitis had positive tests.

\section{HISTOLOGY}

Thirty-one of the 34 biopsies had histological abnormalities (table II). The criteria used in the diagnosis of chronic aggressive hepatitis and chronic persistent hepatitis were those proposed by De Groote, Desmet, Gedick, Korb, Popper, Poulson, Scheuer, Schmid, Thaler, Uelinger, and Wepler (1968). The one biopsy showing cirrhosis also had signs of active inflammation in the portal tracts and piecemeal necrosis indicating that there might have been a preceding chronic aggressive hepatitis. In six of the biopsies showing chronic persistent hepatitis there were foci of inflammation and necrosis in the liver parenchyma. Thirteen other biopsies showed similar foci. These varied in size in different individuals, the smallest consisting of

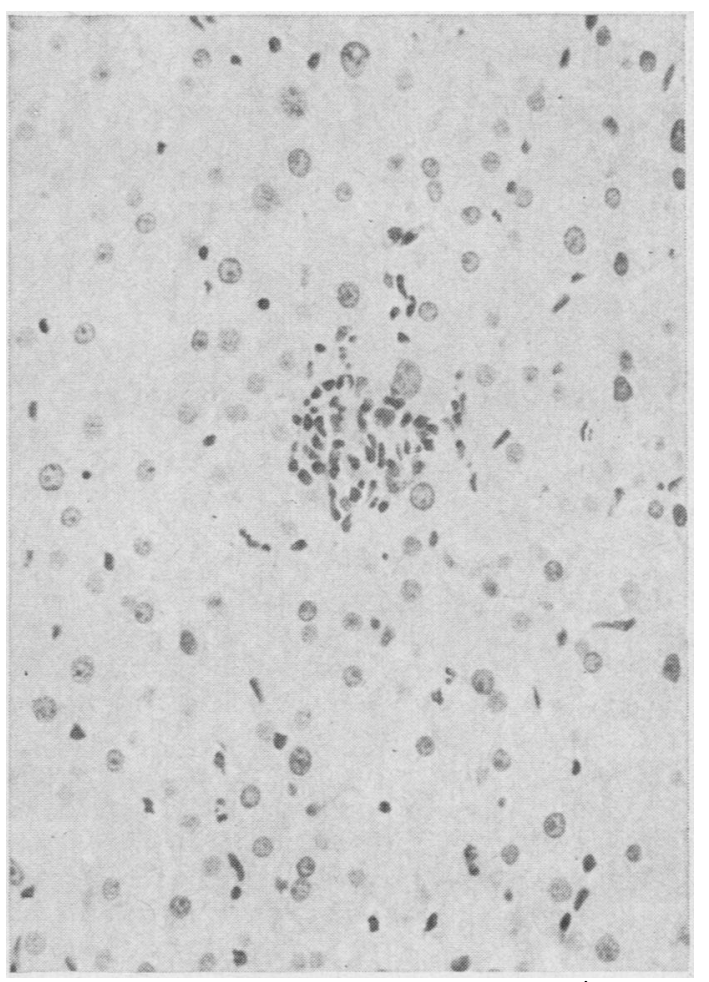

Fig 1 A focus of lymphocytes and histiocytes replacing one or two parenchymal cells. $H \& E \times 332$.

\begin{tabular}{lcccc}
\hline Histological Diagnosis & Total Number of Donors & BSP & $7-11 \%$ \\
\cline { 3 - 5 } & & Normal & 0 & $>11 \%$ \\
\hline Normal & 3 & 3 & 2 & 0 \\
Focal necrosis & 13 & 11 & 5 & 0 \\
Chronic persistent hepatitis & 11 & 5 & 0 & 1 \\
Chronic aggressive hepatitis & 3 & 0 & 1 & 0 \\
Cirrhosis & 1 & 0 & 3 & 0 \\
Incidental lesions & 3 & 0 & 3
\end{tabular}

Table II Correlation of hepatic histology and BSP retention in the 34 donors 


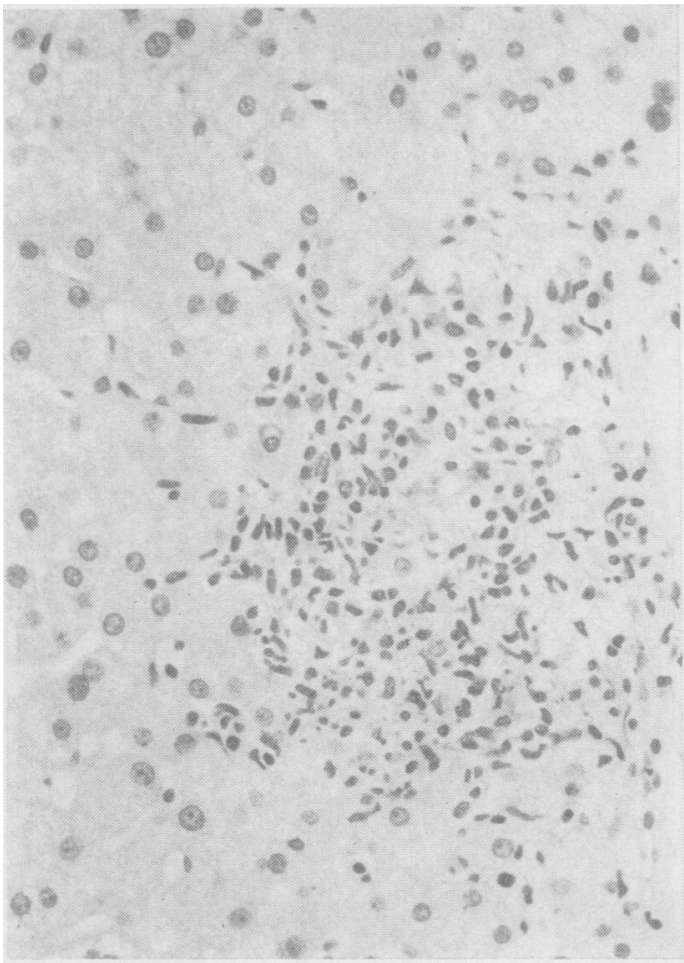

Fig 2

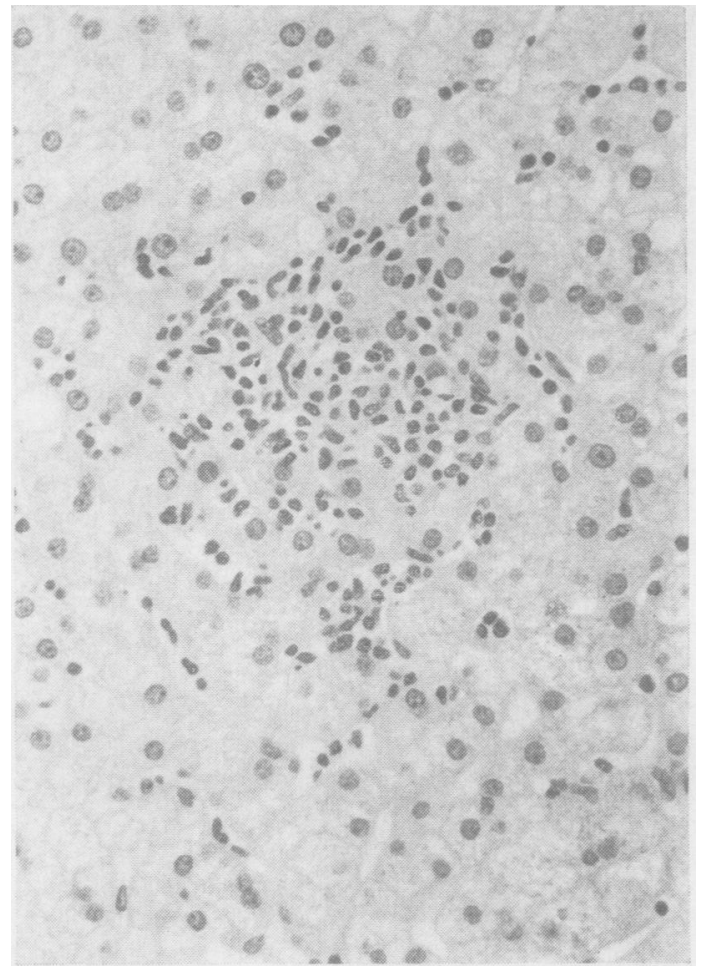

Fig 3

Fig 2 Most of the parenchymal cells in this larger lesion have been replaced by lymphocytes and histiocytes. $H \& E \times 332$.

Fig 3 The inflammatory cells in this larger focus are infiltrating the adjacent normal tissue. $H \& E \times 332$.

aggregations of lymphocytes and histiocytes in which only one or two liver cells had disappeared (fig 1). In larger lesions there was considerable necrosis of the liver parenchyma, most of the parenchymal cells being replaced by lymphocytes and histiocytes (fig 2). In some lesions the inflammatory cells infiltrated the adjacent normal tissue (fig 3). Apparently incidental lesions were seen in three other donors. These were fatty change in two biopsies and multiple granulomata in one.

\section{BIOCHEMICAL CHANGES}

In assessing the cumulative results an SGOT over $40 \mathrm{Karmen}$ units or a serum globulin greater than $3.5 \mathrm{~g} / 100 \mathrm{ml}$ was considered to be abnormal unless detected upon a single occasion only. Mild hyperbilirubinaemia $(1-2 \mathrm{mg} \%$ ) in the absence of other biochemical abnormalities was found in only two donors, one of whom was subsequently shown to have Gilbert's disease. None of the other routine liver function tests were contributory.

Using the above criteria 18 of the 34 donors
$(53 \%)$ had abnormalities of routine liver function tests. This included seven of the 11 donors with chronic persistent hepatitis, the one with cirrhosis, and all three with chronic aggressive hepatitis. Seven of the 17 donors with focal necrosis also had abnormalities of routine liver function. None of the three with normal histology showed any abnormality by the routine tests.

Fifteen BSP retention tests were abnormal (table II) with greater than $6 \%$ retention of a standard $5 \mathrm{mg} / \mathrm{kg}$ dose at 45 minutes. These included the donor with cirrhosis, six of those with chronic persistent hepatitis, and all three with chronic aggressive hepatitis. None of the three donors with normal histology and only two of the 11 with focal necrosis had abnormal BSP retention. The degree of abnormal BSP retention enabled a further separation of the donors to be made (table II). Five of the six donors with chronic persistent hepatitis had a BSP retention of 7 to $11 \%$ and all three donors with chronic aggressive hepatitis had a BSP retention of more than $11 \%$. 


\section{Discussion}

All the donors in this survey were completely asymptomatic and in most instances physical examination was non-contributory. None had ever been jaundiced and in no instance was it possible to identify an illness which might have represented anicteric hepatitis. All the donors had been HBAg positive for a minimum of six months before liver biopsy and all have remained so for at least six months subsequently. All may, therefore, be regarded as established carriers.

The age and sex distributions of the donor sample investigated are comparable to those in other series of volunteer donors (Kliman, Reid, Lilly, and Morrison, 1971; Reinicke, Dybkjaer, Poulsen, Bank, Lylloff, and Nordenfelt, 1972; Wallace et al, 1972). In nearly half of the donors it was not possible to elicit a history of exposure to the antigen. In one third of the donors there was a history of contact with hepatitis, and other possible sources included tattooing and mosquito bites, both of which have been recently incriminated as routes of infection with hepatitis B virus (Mowat, Albert-Recht, Brunt, and Walker, 1973; Prince, Metselaar, Kafuko, Mukwaya, Ling, and Overby, 1972). Two of the donors were hospital employees and it has been suggested that hospital personnel may have an increased frequency of antigen carriage (Soulier, Couroucé-Pauty, and Benamon-Djiane, 1969). One of the important factors revealed by the present study is the high incidence of histological abnormalities in the biopsies and in particular the occurrence of cirrhosis and chronic aggressive hepatitis in asymptomatic HBAg carriers who were not users of narcotics. Chronic aggressive hepatitis has been reported in asymptomatic carriers in only two previous series (Singleton et al, 1971; Bolin et al, 1973) but both these studies included drug addicts and it has been suggested that such use of narcotics itself may be responsible for the production of chronic aggressive hepatitis (Cherubin, Rosenthal, Stenger, Prince, Baden, Strauss, and McGinn, 1972). Chronic persistent hepatitis was present in $11(32 \%)$ of the biopsies. This incidence is in marked contrast to that reported by Reinicke et al (1972) who found only two instances $(8 \%)$ in a comparable study from Denmark. The lesions we have labelled focal parenchymal necrosis have not been described previously in biopsies from HBAg-positive blood donors. They are clearly much larger than the minor parenchymal lesions described by Ricci, De Bac, and Caramia (1972) and their significance may become apparent in later studies.

The explanation for the spectrum of histological changes encountered is at present obscure. Our investigations have failed to confirm the suggestion (Dudley et al, 1971) that there is a correlation between the severity of liver damage and the titre of the antigen in the serum. The low incidence of autoantibodies in this series $(15 \%)$ is in contrast to Holborow's (1972) finding of smooth muscle antibodies in $38 \%$ of 56 asymptomatic carriers. There was in addition no correlation between the presence of autoantibodies and the extent of histological damage.

Serial biochemical investigations may be of some value in predicting histological abnormalities. All three donors with chronic aggressive hepatitis and the donor with cirrhosis had abnormal routine liver function tests. In two instances, however, these abnormalities were only revealed by repeated testing over a period of one year. The incidence of liver function test abnormalities in the donors with chronic persistent hepatitis was also increased by repeated testing. None of the donors with normal liver histology had abnormalities of routine liver function even with repeated testing, but seven of the 13 with focal parenchymal necrosis had abnormal tests at some time during the period of follow up. Standard liver function tests did not discriminate between persistent hepatitis and chronic aggressive hepatitis. Such discrimination appeared to be achieved by means of the BSP retention tests. In the donors with chronic aggressive hepatitis $12 \%$ or more retention was found but in the donors with persistent hepatitis the retention was usually less than $12 \%$.

As a result of our present findings we would suggest that all persons who are found to be persistent HBAg carriers should have routine liver function tests performed on several occasions over a period of at least six months. Where abnormalities are detected further evaluation should be made by means of BSP retention tests. Liver biopsy will be necessary to differentiate between the two types of chronic hepatitis.

We wish to thank the members of our nursing and medical staff who assisted in the care of these patients, and Miss Ann Woolfenden who coordinated the investigation programme. It is a pleasure to acknowledge the encouragement and advice of Professor J. M. Evanson.

References

Beck, J. S. (1961). Variations in the morphological patterns of 'autoimmune' nuclear fluorescence. Lancet, 1, 1203-1205.

Bolin, T. D., Davis, A. E., and Liddelow, A. G. (1973). Liver disease and cell-mediated immunity in hepatitis-associated antigen (HAA) carriers. Gut, 14, 365-368.

Cherubin, C. E., Rosenthal, W. S., Stenger, R. E., Prince, A. M., Baden, M., Strauss, R., and McGinn, T. G. (1972). Chronic liver disease in asymptomatic narcotic addicts. Ann. intern. Med., 76, 391-395. 
De Groote, J., Desmet, V. J., Gedick, P., Korb, G., Popper, H., Poulsen, H., Scheuer, P. J., Schmid, M., Thaler, H., Uehlinger, E., and Wepler, W. (1968). A classification of chronic hepatitis. Lancet, 2, 626-628.

Dudley, F. J., Fox, R. A., and Sherlock, S. (1971). Relationship of hepatitis-associated antigen (HAA) to acute and chronic liver injury. Lancet, 2, 1-3.

Goudie, R. B., MacSween, R. N. M., and Goldberg, D. M. (1966). Serological and histological diagnosis of primary biliary cirrhosis. J. clin. Path., 19, 527-538.

Hadziyannis, S. J., Merikas, G. E., and Afroudakis, A. P. (1970). Hepatitis-associated antigen in chronic liver disease. Lancet, $2,100$.

Holborow, E. J. (1972). Smooth-muscle autoantibodies, viral infections and malignant disease. Proc. roy. Soc. Med., 65, 481-484.

Johnson, G. D., Holborow, E. J., and Glynn, L.E.(1965). Antibody to smooth muscle in patients with liver disease. Lancet, 2, 878-879.

Kliman, A., Reid, N. R., Lilly, C., and Morrison, J. (1971). Hepatitisassociated antigen (Australia antigen) in Massachusetts blood donors. New Engl. J. Med., 285, 783-785.

Krohn, K., Finlayson, N. D. C., Jokelainen, P. T., Anderson, K. E., and Prince, A. M. (1970). Electron microscopical and immunological observations on the serum-hepatitis (S.H.) antigen in primary biliary cirrhosis. Lancet, 2, 379-383.

Mowat, N. A. G., Albert-Recht, F., Brunt, P. W., and Walker, W.
(1973). Outbreak of serum hepatitis associated with tattooing. Lancet, 1, 33-34.

Prince, A. M., Metselaar, D., Kafuko, G. W., Mukwaya, L. G., Ling, C. M., and Overby, L. R. (1972). Hepatitis B antigen in wild-caught mosquitoes in Africa. Lancet, 2, 247-250.

Reinicke, V., Dybkjaer, E., Poulsen, H., Banke, O., Lylloff, K., and Nordenfelt, E. (1972). A study of Australia-Antigen-Positive blood donors and their recipients, with special reference to liver histology. New Engl. J. Med., 286, 867-870.

Ricci, G., De Bac, C., and Caramia, F. (1972). Liver disease in Australia antigen carriers. Lancet, 1, 494.

Singleton, J. W., Fitch, R. A., Merrill, D. A., Kohler, P. F., and Rettberg, W. A. H. (1971). Liver disease in Australia-AntigenPositive blood-donors. 2, Lancet, 785-787.

Soulier, J. P., Couroucé-Pauty, A. M., and Benamon-Djiane, D. (1969). Etude immunologique des hépatités à virus recherche de l'antigene Australia et a l'anticorps correspondant: premiers résultats. Rev. franc. Transfusion, 12, 361-382.

Stratton, F. (1972). Recherche de l'antigène Australia antigéne associè à l'hépatite-HAA) et de son anticorps dans le service national de transfusion sanguine de Grande-Bretagne. Rev. franc. Transfusion, 15, 415.

Wallace, J., Milne, G. R., and Barr, A. (1972). Total screening of blood donations for Australia (hepatitis associated) antigen and its antibody. Brit. med. J., 1, 663-664. 